\title{
Efficacy of Human Platelet Rich Fibrin Exudate ws Fetal Bovine Serum on Proliferation and Differentiation of Dental Pulp Stem Cells
}

\author{
Mahmoud A. Saeed ${ }^{1}$, Mohamed Abd El-Rahman ${ }^{2}$, Mohamed E. Helal ${ }^{2}$, \\ Ahmed R. Zaher ${ }^{2}$, Mohammed E. Grawish ${ }^{1,2}$ \\ ${ }^{I}$ Department of Oral Biology, Faculty of Oral and Dental Medicine, Delta University for Science and Technology, Gamasa, Mansoura, Egypt, \\ ${ }^{2}$ Department of Oral Biology, Faculty of Dentistry, Mansoura University, Mansoura, Egypt
}

Background and Objectives: The imperative role of dental pulp stem cells (DPSCs) in regenerative therapy demands an in-vitro expansion which must deal with the safety and ethical problems associated with fetal bovine serum (FBS). The primary aim of this study was to compare the effects of human platelet rich fibrin (hPRF) exudate Vs FBS on proliferation and osteodifferentiation of human dental pulp stem cells (hDPSCs). The secondary one was to determine the optimum concentration of hPRF exudate inducing hDPSCs proliferation and osteodifferentiation.

Methods: The direct method was used to prepare hPRF exudate. hDPSCs were isolated from impacted mandibular third molars of twelve donors by the outgrowth method. For cell viability and proliferation rate testing, 96 well plates were used and the assay was done in duplicate and the trial repeated four times under the same conditions. Six wells were used to contain $10 \% \mathrm{FBS}$, serum free media, $1 \%, 5 \%, 10 \%$ and $20 \%$ concentrations of hPRF exudates, respectively. The proliferation assay was carried out by MTS tetrazolium cell proliferation assay kit and Elisa reader. The study design for osteodifferentiation protocol was exactly as the proliferation one and instead the assay was carried out by alizarin red with Elisa reader.

Results: Compared to $10 \%$ FBS, $10 \% \mathrm{hPRF}$ exudate was the optimum concentration for hDPSCs proliferation, while $1 \% \mathrm{hPRF}$ exudate was the optimum concentration for osteodifferentiation of hDPSCs.

Conclusions: Avoiding the risk of zoonosis which may be occurred with FBS, it is recommended to use $10 \% \mathrm{hPRF}$ exudate for proliferation and $1 \%$ for osteodifferentiation.

Keywords: Human platelet rich fibrin exudate, Fetal bovine serum, Dental pulp stem cells, MTS cell proliferation assay, Alizarin Red S staining assay

\footnotetext{
Accepted for publication January 27, 2017, Published online May 30, 2017 Correspondence to Mohammed E. Grawish

Department of Oral Biology, Faculty of Dentistry, Mansoura University, Mansoura 35516, Egypt

Tel: +02-50-6328744, Fax: +02-50-2200706

E-mail: grawish2005@yahoo.com

(c) This is an open-access article distributed under the terms of the Creative Commons Attribution Non-Commercial License (http://creativecommons.org/ licenses/by-nc/4.0/), which permits unrestricted non-commercial use, distribution, and reproduction in any medium, provided the original work is properly cited.

Copyright (c) 2017 by the Korean Society for Stem Cells Research
}

\section{Introduction}

Expansion and culture of mesenchymal stem cells (MSCs) in-vitro depends on supplementing culture medium with fetal bovine serum (FBS) or fetal calf serum (FCS) that contains numerous growth factors inducing cell attachment, proliferation, and differentiation (1). Protracted expansion times, risk of xenogenic response, exposure to zoonosis and allergic side effects create obstacles for the use of FBS in clinical trials. Therefore, an alternative supplement with proper inherent growth-promoting activities was demanded (2).

Human-derived medium additives, that can replace 
FBS, have been investigated in the past few years and have led to the discovery of efficient alternatives such as autologous plasma-derived from bone marrow (BM), human platelet lysates (hPL), collagen-activated platelet releasates, thrombin-activated platelet releasates, autologous and allogeneic human serum albumin and human serum (3). Although these products are from human origin, these sera show batch-to-batch variability that may affect reproducibility (4).

Under optimal conditions of standardization and safety, hPL was produced through platelet lysis and has been increasingly suggested as the future 'gold standard' supplement replacing FBS for the ex-vivo propagation of MSCs for cell therapy applications and translational medicine (5). hPL has higher concentration of grown factors and is effective in maintaining growth and stem cell phenotype (6). The disadvantage of hPL is the high cost preparation, time consuming, donor to donor variability and recurrent freezing and thawing process that causes protein denaturation. The plasma components of hPL necessitate addition of anticoagulants such as heparins to prevent gelatinization of hPL medium, and their concentration must be standardized (7).

The possibility of obtaining soluble platelet-derived factors by platelet activation (releasate; the product obtained following platelet-rich plasma activation) had been demonstrated. While hPL preparations liberate the entire contents of the platelets and contain aggregates of platelet membranes, thrombin activation triggers a burst of growth factor release that mimics what happens in-vivo during wound healing and tissue repair (8). Platelet-rich plasma releasate was able to prevent cellular chondrogenic capacity loss (9) and can be used for ex-vivo expansion of corneal endothelium cells (10). A disadvantage of platelet activation is the requirement of using exogenous substance, thus increasing the risk of allergic reactions and infection, especially with the use of bovine substance which is immunogenic (11).

Platelet rich fibrin (PRF) can be prepared solely through the activation of an endogenous coagulation process without the aid of animal-derived coagulants such as bovine thrombin. Freshly prepared PRF clots were compressed into a thin membrane by PRF compression device to get rid of PRF exudate (12). PRF exudate is superior to platelet rich plasma (PRP), from the aspects of expression of alkaline phosphatase and induction of mineralization (13). Currently, little information is available on the effect of human PRF (hPRF) exudate on the efficacy of human dental pulp stem cells (hDPSCs) in normal and osteogenic culture media (CM). This study aimed to eval- uate the biological influence of various concentrations of hPRF exudate on the proliferation and osteodifferentiation of hDPSCs. The research null hypothesis was that no effect for hPRF exudate on hDPSCs proliferation and osteodifferentiation.

\section{Materials and Methods}

\section{Preparation of hPRF exudate}

In accordance with our institutional ethics committee, hPRF exudate was prepared from 8 healthy donors who had visited the outpatient clinic at Faculty of Dentistry, Delta University for Science and Technology, Egypt. They were non smokers and non alcoholic, 4 of them were males and the others were females with age range (20 to 30 years) after obtaining their informed consent. One hundred and forty millimeter of blood was collected. The blood samples were centrifuged in centrifugation machine (Sigma Aldrich) at $2700 \mathrm{rpm}$ for $12 \mathrm{~min}$. A white PRF clot was formed between the acellular plasma and RBCs. The PRF clot was held by sterile forceps and separated from RBCs by scissor. The clot was placed on the grid of endobox and compressed by endobox cover. After 1 min, PRF clot was converted into PRF membrane and the exudate was collected in the tray of the endobox. PRF exudate was centrifuged at $1800 \mathrm{rpm}$ for $5 \mathrm{~min}$ to obtain exudate only without RBCs which were precipitated. The exudate was filtered by $0.22 \mu \mathrm{m}$ sterile syringe filter unit (Millipore Corporation, Bedford, MA 01730). PRF exudate was stored in eppendorf tubes at $-20^{\circ} \mathrm{C}$ immediately after preparation. The final PRF exudate concentration $(1 \%, 5 \%, 10 \%$ and $20 \%)$ was calculated on the basis of the volume of PRF exudate that was added to the total volume of the CM.

\section{Isolation of dental pulp stem cells}

Twelve impacted third molars from 12 donors were extracted and used for DPSCs isolation with written permission. The ethics committee of our institution approved the experimental protocol. The inclusion criteria for selection were 1) patients free of any systemic or local diseases affecting dental tissues, 2) mean age of 19 22 years, 3) vertically impacted third molar and 4) sound non-carious teeth. Surgeries were carried out at Oral and Maxillofacial Surgery Department, Faculty of Dentistry, Delta University for Science and Technology. Surgeries were carried out under meticulous sterile conditions.

The extracted teeth were irrigated immediately and consecutively for $15 \mathrm{~s}$ after extraction with saline, 70\% ethyl chloride, and phosphate buffer saline (PBS, Gibco). After 
irrigation, the teeth were preserved in sterile falcon tube containing pasteurized milk. The extracted teeth were transported to Nile Experimental Private Center for Researches under careful aseptic conditions. All the following steps were done in the laminar flow hood under meticulous aseptic conditions. The teeth with the pasteurized milk were put in sterile culture dish. All soft tissue attached to the extracted teeth was removed using sterile curette, then the teeth were irrigated with chlorhexidene (Kenara mouth wash; Macro Group Pharmaceuticals) followed by PBS. The pulp of each tooth was harvested using Hand Held Pulp Isolator device (designed by Ahmed Shetewy, a student at Faculty of Dentistry, Mansoura University under supervision of Prof/Yousry EL-Hawary, Oral Biologist at Oral Biology Department). Briefly, the tooth was sunken in PBS and rested on its most widest and regular surface in the device. The tooth was splinted in two parts using the device handle. The two parts were put in sterile dish and the pulp was dissected from the surrounding hard tissue using the blunted side of small excavator. Each pulp tissue was cut horizontally into ten fragments using two scalpels moved in a cross manner.

The method of DPSCs isolation was carried out using direct outgrowth method from pulp tissue explants. Briefly, pulp pieces were cultured in $25 \mathrm{~cm}^{2}$ flask (Greiner) with $10 \mathrm{ml}$ Dulbecco's Modified Eagle Media- Ham's F12 (DMEM/F12; lonza) supplemented with 10\% FBS (Gibco) and $1 \%$ streptomycin and penicillin (Gibco), then the cultured pieces were incubated at $37^{\circ} \mathrm{C}$ and $5 \% \mathrm{CO}_{2}$ atmosphere. Examination by inverted light microscope (Olympus) was carried out daily and the CM was changed every three days. When the cell colony formation units reached $80 \%$ confluence, the cells were transferred to $75 \mathrm{~cm}^{2}$ flask and this was passage one. Feeding was continued with the protocol of cell culturing and cells at passage six were used for this study. During passaging, cells were transported from flask to another one with trypsenization process aiming to de-adhering cells from the flask.

\section{Direct staining method for surface marker characterization and flow cytometry}

The cells were incubated with specific individual monoclonal antibodies, conjugated with fluorescein isothiocyanate (FITC), phycoerythrin (PE), or peridinin chlorophyll protein in $250 \mathrm{ml}$ PBS for $30 \mathrm{~min}$ in the dark at room temperature. The primary antibodies used were CD34-PE which distinguishes hematopoietic stem cells, progenitor cells and endothelial cells, CD45 considered as anti-leukocyte common antigen, CD90 involved in wound repair, cell-cell and cell-matrix interactions and CD105 that mod- ulates TGF-beta functions via interaction with TGF-beta RI and TGF-beta RII (14). Acquisition and analysis for CD34 and CD45 were done by fluorescein activated cell sorting $\{($ FACS $)$ Canto, BD, USA $)\}$ and the data were analyzed with BD CellQuest ${ }^{\mathrm{TM}}$ Pro version 6.0 software. Meanwhile the analysis for CD105 and CD90 were performed with a BD Accuri C6 flow cytometer and BD Accuri C6 program software.

\section{Proliferation assay}

According to the PRF exudate concentrations, six wells of 96-well plate were used. The assay was done in duplicate and the trial repeated four times under the same conditions. Each well contained $2 \times 10^{3}$ cells with $200 \mu 1$ of complete media. They were incubated at $37^{\circ} \mathrm{C}$ and $5 \%$ $\mathrm{CO}_{2}$ atmosphere over night till cells became adhered. After cells adhesion, they were incubated for $24 \mathrm{~h}$ with serum free media (SFM) at $37^{\circ} \mathrm{C}$ and $5 \% \mathrm{CO}_{2}$ atmosphere. As proliferation was measured after $1^{\text {st }}$ and $3^{\text {rd }}$ day, 2 of 96 well plates were used. In the first well, the complete media was supplemented with $10 \%$ FBS and considered as positive control. While the second one, contained cells with SFM only and considered as negative control. In the $3^{\text {rd }}, 4^{\text {th }}, 5^{\text {th }}$ and $6^{\text {th }}$ wells, the complete media were supplemented with $1 \%, 5 \%, 10 \%$, and $20 \%$ PRF exudate, respectively. $100 \mu \mathrm{l}$ of $\mathrm{CM}$ were removed from each well and $100 \mu 1$ of 3-(4, 5-dimethyl thiazol-2-yl)-5-(3-carboxymethoxyphenyl)-2-(4-sulfophenyl)-2H tetrazolium inner salt (MTS; promega) were added using pipette tip. The plate was incubated at $37^{\circ} \mathrm{C}$ and humidified at $5 \% \mathrm{CO}_{2}$ atmosphere for $4 \mathrm{~h}$. The absorbance was recorded at 490 nm using 96 well plate readers "Elisa reader".

\section{Osteogenic differentiation assay}

The osteogenic differentiation media was consisted of nutritional media (DMEM-F12), $50 \mu \mathrm{g} / \mathrm{ml}$ of L-ascorbic acid 2-phosphate, $10 \mathrm{mM}$ of $\beta$-glycerophosphate sodium salt, $10 \mu \mathrm{M}$ of dexamethasone and antibiotics $(100 \mathrm{mg} / \mathrm{ml}$ streptomycin and $100 \mu / \mathrm{ml}$ penicillin-G). For osteogenic differentiation four of 6 -well plates were used. $1 \times 10^{5}$ cells/well in the 6 well plates were cultured with complete media till reach nearly $70 \%$ confluences and then incubated with $\mathrm{SFM}$ at $37^{\circ} \mathrm{C}$ and $5 \% \mathrm{CO}_{2}$ for $24 \mathrm{~h}$. The cells were maintained in osteogenic differentiation media with the different concentrations of PRF exudate. Each well in the 6-well plate contains specific concentration as in the following; $10 \%$ FBS, media only, $1 \%, 5 \%, 10 \%$ and $20 \%$ of PRF exudate. Media was changed every 3 days. Formation of the mineralized nodules was detected and quantified after 7 days by Alizarin red-based assay. This 
assay was carried out according to the protocol of Carl A. Gregory et al. (15). Briefly, the cells in the 6-well plates were washed with PBS and fixed for $15 \mathrm{~min}$ in $10 \%$ (v/v) formaldehyde at room temperature. The cells were then washed twice with an excess of $\mathrm{dH}_{2} \mathrm{O}$ before the addition of $250 \mu 1$ of $40 \mathrm{mM}$ Alizarin Red S (pH 4.1) per well. The plates were incubated at room temperature for $20 \mathrm{~min}$ with gentle shaking. After aspiration of the unincorporated dye, the wells were washed four times with $1 \mathrm{ml}$ $\mathrm{dH} 2 \mathrm{O}$ during a $5 \mathrm{~min}$ shaking. The stained monolayers were visualized by phase inverted microscope (Olympus Optical Co., Ltd., Japan). For the quantification of staining, $200 \mu 110 \%$ (v/v) acetic acid was added to each well, and the plate was incubated at room temperature for 30 min with shaking. The monolayer was then scraped from the plate with a cell scraper and transferred with $10 \%$ (v/v) acetic acid to an eppendorf tubes. After the slurry was vortexed for 30s, it was overlaid with $125 \mu 1$ mineral oil (Sigma-Aldrich), heated to exactly $85^{\circ} \mathrm{C}$ for $10 \mathrm{~min}$, and transferred to ice for $5 \mathrm{~min}$. The slurry was then centrifuged at $14799 \mathrm{rpm}$ for $15 \mathrm{~min}$, and $125 \mu$ of the supernatant was transferred to a new eppendorf tubes. Then, $50 \mu 1$ of $10 \%(\mathrm{v} / \mathrm{v})$ ammonium hydroxide was added to neutralize the acid. Aliquots $(150 \mu 1)$ of the supernatant were read at $405 \mathrm{~nm}$ in 96-well plate. All these steps were repeated at least three times.

\section{Statistical analysis}

Statistical analyses were performed using SPSS software (version 20). The effects of the different concentrations of hPRF exudate on hDPSCs viability (proliferation) were analyzed using two way-ANOVA statistical test while the data of osteodifferentiation were analyzed using one way-ANOVA. Factors for the two way-ANOVA were 1) different concentrations 2) different time periods while the factor for one way-ANOVA was the different concentrations.

Cell viability ratio was calculated as follow:

1) First, normalization of each well containing different
A

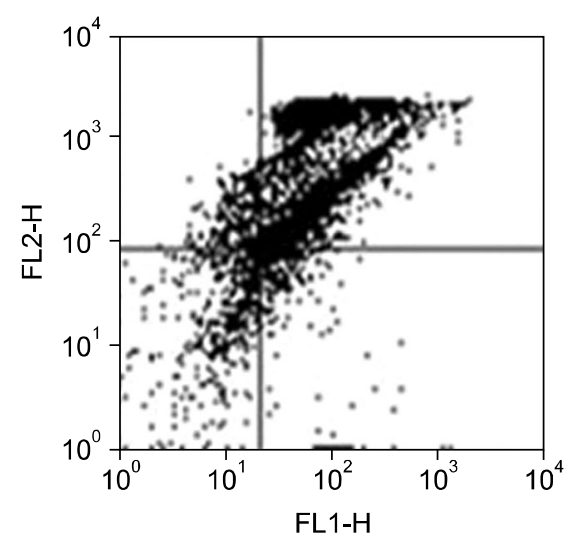

B

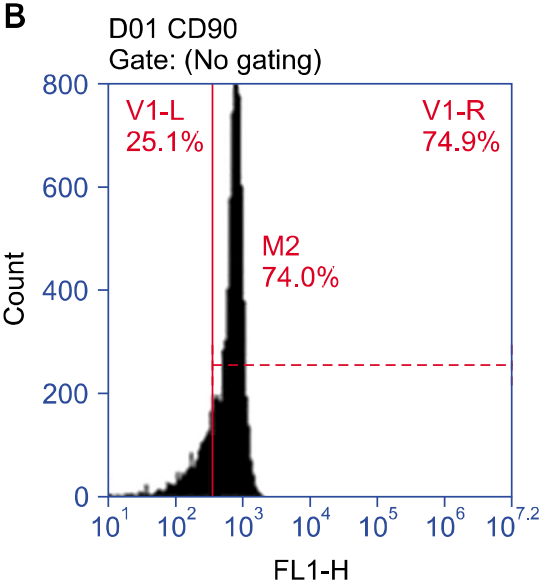

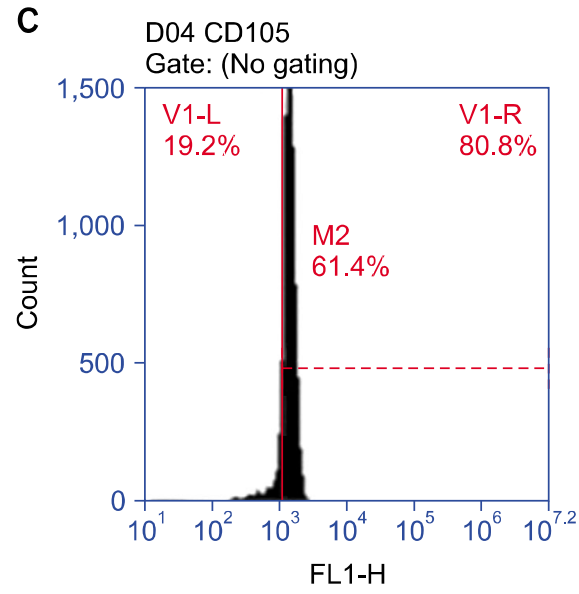

Fig. 1. Flow cytometry chart showing double stain for CD34 (FL1-H) \& CD45 (FL2-H) (A) and single parameter histogram for CD90 and CD105 (B and C). Flow cytometric analysis showing the negative reaction of CD34 (6.8\%) and CD45 (6.8\%) to hDPSCs while their clusters were positive to CD90 (74.0\%) and CD105 (61.4\%).

Table 1. Two way-ANOVA and LSD post-hoc statistical test for the effects of FBS, SFM and PRF different concentrations on hDPSCs viability at the different time periods

\begin{tabular}{cccccccccc}
\hline \multicolumn{2}{l}{ Two way-ANOVA (F ratio and $p$ value) } \\
\hline \multicolumn{1}{l}{ Concentrations } & Time & Interaction & Periods & $10 \%$ FBS & SFM & $1 \%$ PRF & $5 \%$ PRF & $10 \%$ PRF & $20 \%$ PRF \\
\hline$(28.952$, & $(3.120$, & $(6.223$, & 1 day & $100.00^{\dagger} \pm 0.00$ & $62.73 \pm 1.27$ & $41.36 \pm 1.41$ & $66.56 \pm 2.80$ & $109.48^{\dagger} \pm 3.19$ & $65.86 \pm 7.77$ \\
$\left.0.001^{*}\right)$ & $\left.0.081^{*}\right)$ & $\left.0.001^{*}\right)$ & 3 day & $100.00^{\dagger} \pm 0.00$ & $58.60 \pm 1.26$ & $58.49 \pm 4.81$ & $62.65 \pm 0.88$ & $71.76^{\dagger} \pm 3.92$ & $63.51 \pm 3.61$ \\
\hline
\end{tabular}

LSD: least significant difference, ANOVA: analyses of variance, FBS: fetal bovine serum, SFM: serum free medium, PRF: platelet rich fibrin. $\mathrm{p}<0.05$.

*Two way-ANOVA.

${ }^{\dagger}$ Non-significant compared to $10 \%$ FBS.

Differences $(p<0.05)$ between two periods were not observed for any of the variable. 

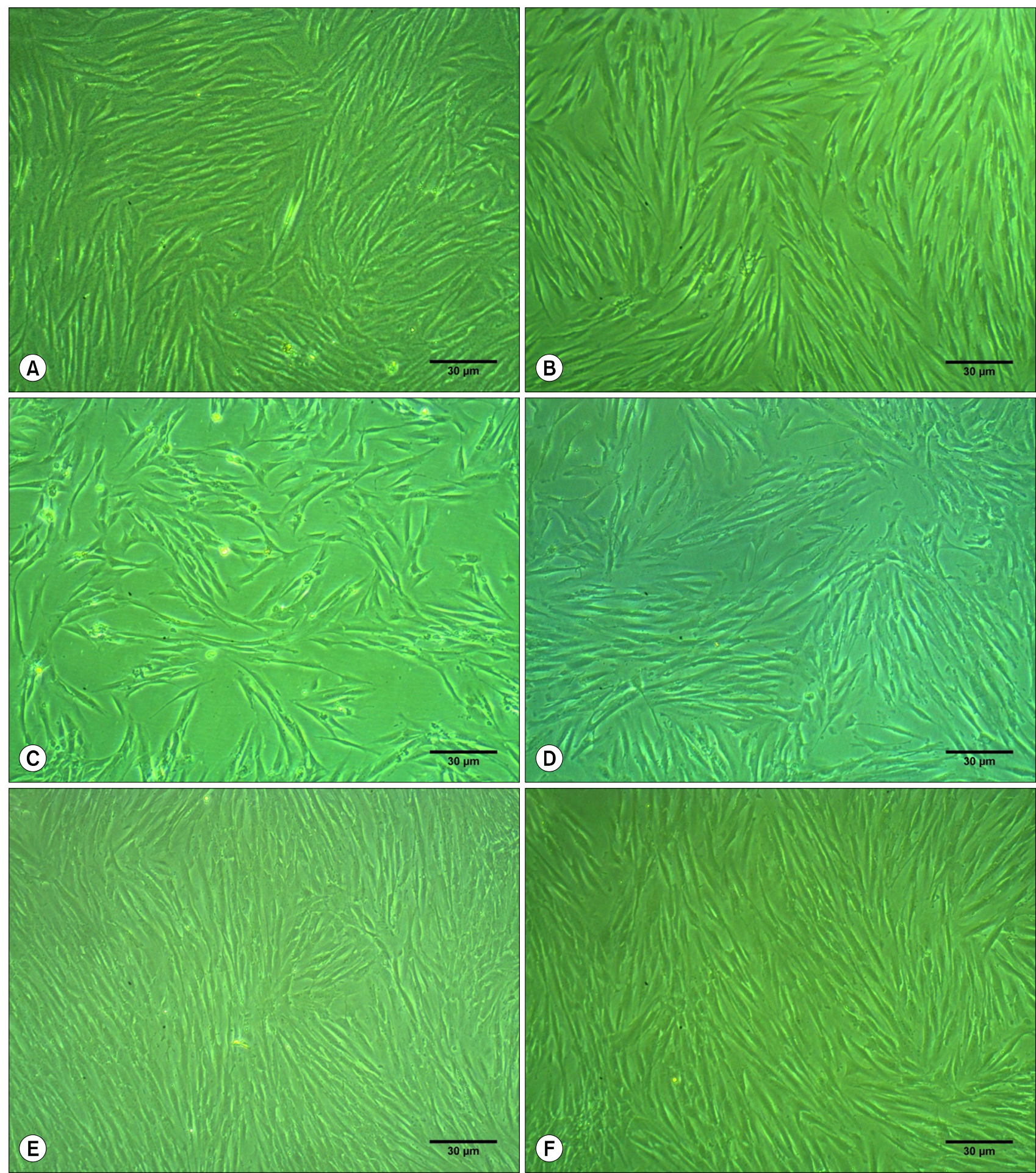

Fig. 2. Inverted light microscopic representative images at $10 \times$ magnification showing hDPSCs colony formation capacity and proliferation rates after 3 days with $10 \%$ FBS $(100.00 \pm 0.00$; A), SFM $(62.73 \pm 1.27, B)$, with $1 \%$ PRF exudate $(41.36 \pm 1.41$; C), with $5 \%$ PRF exudate $(66.56 \pm 2.80 ; \mathrm{D})$, with $10 \%$ PRF exudate $(109.48 \pm 3.19 ; \mathrm{E})$ and $20 \%$ PRF exudate $(65.86 \pm 7.77$; F), Scale bar $=30 \mu \mathrm{m}$.

concentration was done by subtracting the absorbance of the blank wells (medium without cells) from the absorbance of all wells (SFM, 10\% FBS, 1\%PRF, 5\% PRF, 10\%
PRF and 20\% PRF exudate).

2) Second, the mean absorbance of $10 \%$ FBS served as reference value for cell viability. The cell viability was cal- 
culated using the following equation:

$$
\frac{\text { Absorbance of each concentration }}{\text { Absorbance of } 10 \% \text { FBS }} \times 100
$$

Data are expressed as mean \pm SD. For all tests, statistical significances were accepted for $\mathrm{p}$ values of $<0.05$.

\section{Results}

\section{Characters of hPRF exudate}

The PRF exudate obtained was yellowish clear fluid. Each $50 \mathrm{ml}$ blood sample produced $4.5 \mathrm{ml}$ PRF exudate.

\section{Morphology of the cultured hDPSCs}

At the $3^{\text {rd }}$ day, few numbers of rounded cells were adhered to the flask while at the $6^{\text {th }}$ day, cell adherence to the flask was increased and some rounded cells were converted to star shaped cells with the majority of them were rounded in shape. At $11^{\text {th }}$ day, 3 colonies of cells were notified. At the $19^{\text {th }}$ day, cell confluence was notified. At this stage all adhered cells were spindle shaped cells.

\section{Flow cytometry characterization}

Firstly, in order to characterize the whole population of DPSCs, the expression of stem cell surface markers was analyzed by flow cytometry. The results of flow cytometric analysis revealed that hDPSCs were negative to CD34 (6.8\%) and CD45 (6.8\%) while their clusters were positive to $\mathrm{CD} 90(74.0 \%)$ and $\mathrm{CD} 105$ (61.4\%) (Fig. 1).

\section{Proliferation results}

The objective of this experiment was to examine the effect of various concentrations of hPRF exudate on proliferation of hDPSCs in-vitro. The effect was evaluated by assessing cell viability using the MTS assay. Compared to $10 \% \mathrm{FBS}$, the results of the present study showed that $10 \% \mathrm{hPRF}$ exudate increased proliferation of hDPSCs at the $1^{\text {st }}$ day and had an inhibitory growth pattern for hDPSCs at the $3^{\text {rd }}$ day. Despite the inhibitory pattern at the $3^{\text {rd }}$ day, $10 \%$ hPRF exudate still had the highest proliferative capability compared to the other various hPRF concentrations. Two way-ANOVA statistical test for the continuous data revealed a significant difference between different groups $(\mathrm{F}$ ratio $=28.952, \mathrm{p}=0.001)$, non-significant difference between different time periods $(F$ ratio $=3.120$, $\mathrm{p}=0.081$ ) and a significant interaction between the time periods and the groups ( $\mathrm{F}$ ratio $=6.223, \mathrm{p}=0.001$ ) (Table $1)$. The highest mean values for the cell viability was for $10 \%$ PRF exudate at 1 day $(109.48 \pm 3.19)$ while the lowest one was for $1 \%$ PRF (41.36 \pm 1.41$)$. The cell viabilities mean values at 1 day for $10 \% \mathrm{FBS}, \mathrm{SFM}, 5 \% \mathrm{PRF}$ and $20 \%$ PRF were $100.00 \pm 0.00,62.73 \pm 1.27,66.56 \pm 2.80$ and $65.86 \pm 7.77$, respectively. Furthermore, the cell viabilities mean values at 3 day for 10\% FBS, SFM, 1\%PRF, 5\% PRF, $10 \%$ PRF and $20 \% \mathrm{PRF}$ were $100.00 \pm 0.00$, $58.60 \pm 1.26, \quad 58.49 \pm 4.81, \quad 62.65 \pm 0.88, \quad 71.76 \pm 3.92$ and 63.51 \pm 3.61 , respectively (Table 1, Figs. 2 and 3). There were significant differences between 10\% FBS \& SFM, $10 \%$ FBS \& 1\% PRF, $10 \%$ FBS \& 5\% PRF, 10\% FBS \& $20 \%$ PRF, SFM \& 1\% PRF, SFM \& 10\% PRF, 1\% PRF \& $5 \%$ PRF, $1 \%$ PRF \& 10\% PRF, $1 \%$ PRF \& 20\% PRF, $5 \%$ PRF \& 10\% PRF, 10\% PRF \& 20\% PRF (Table 1, Figs. 2 and 3).

\section{Osteodifferentiation results}

To investigate the mineralization potential of hDPSCs undergoing osteogenic differentiation, we assessed Alizarin Red S staining using the MTS assay. The mineralized nodules were clearly formed and stained with Alizarin Red within all wells. There were obvious differences in the amounts of mineralization among the different groups. In particular, the mineralized nodules progressively increased with $1 \%$ PRF exudate at the $7^{\text {th }}$ day of culture with the osteogenic medium (Fig. 4). One way-ANOVA statistical test for the continuous data revealed a total significant difference among different groups $(\mathrm{F}$ ratio $=42.26, \mathrm{p}=0.001)$ (Table 2). The highest mean values for the optical density (absorbance) was for $1 \%$ PRF exudate $(0.1913 \pm 0.006)$ while the lowest one was for $10 \%$ FBS $(0.1095 \pm 0.004)$. The mean values for SFM, 5\% PRF, 10\% PRF and 20\% FBS

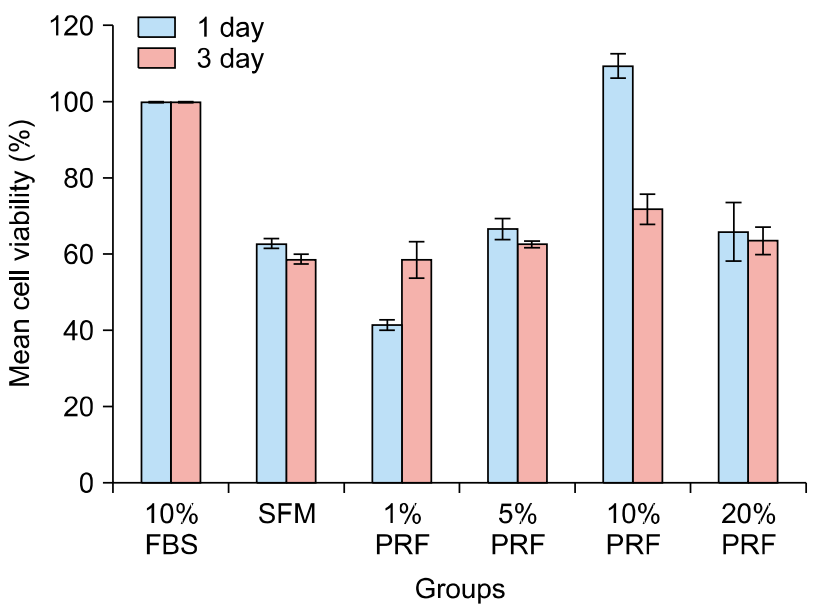

Fig. 3. Bar chart and error bars for cell viability (\%) as measured by absorbance of hDPSCs at $490 \mathrm{~nm}$ after culturing in 96-well plate with FBS, SFM and the PRF different concentrations at the two time periods, data are the mean \pm SD. 

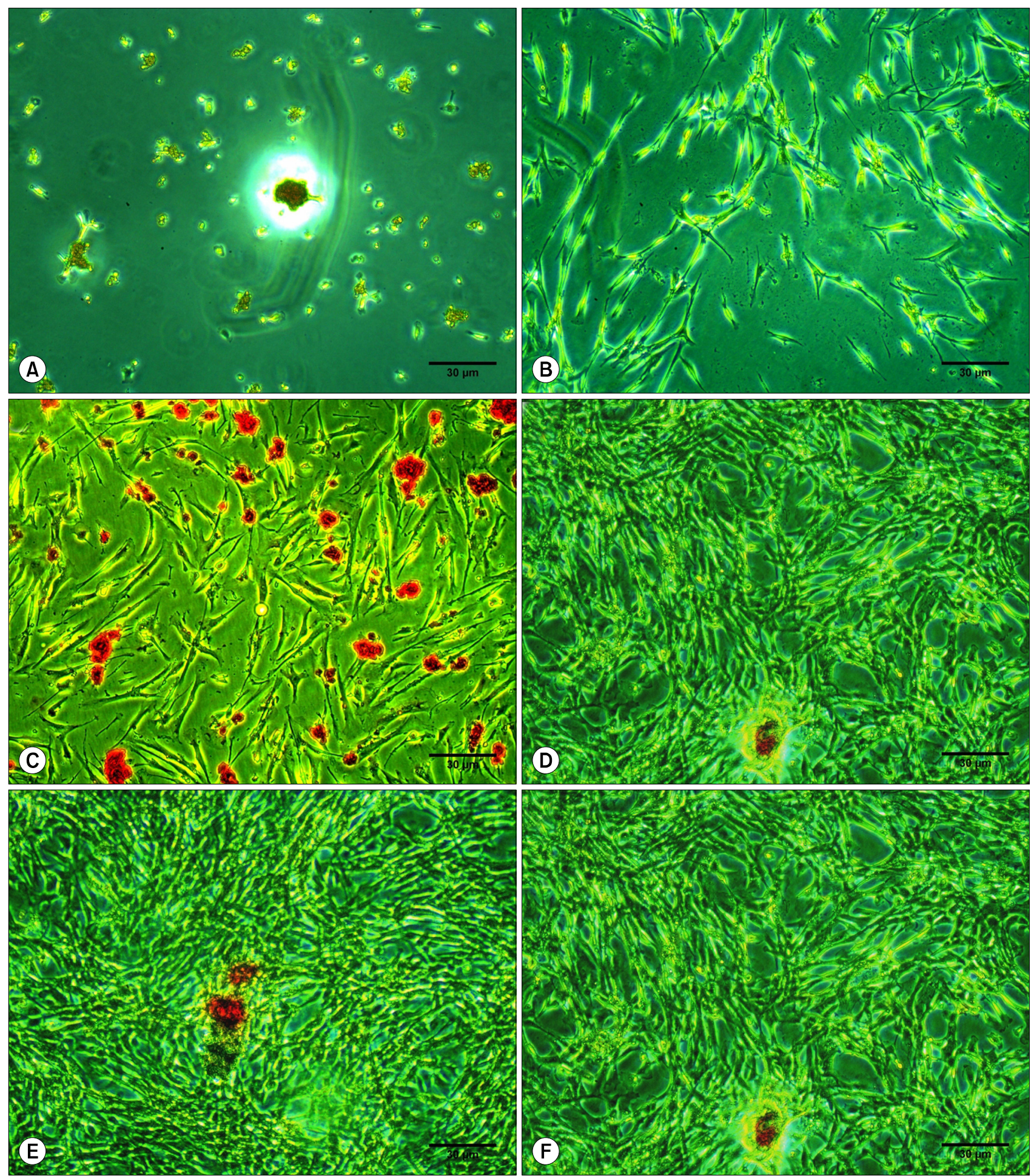

Fig. 4. Mineralized deposit identified by Alizarin Red S staining in cells grown in osteogenic medium at the $7^{\text {th }}$ day. Alizarin Red $\mathrm{S}$ staining of hDPSCs as viewed under the inverted light microscope at $10 \times$ magnification with $10 \%$ FBS $(0.004 \pm 0.1095 ; A)$, osteodifferentiation media only $(0.006 \pm 0.1273 ;$ B), $1 \%$ PRF exudate $(0.006 \pm 0.1913 ; C), 5 \%$ PRF exudate $(0.1273 \pm 0.006 ;$ D), $10 \%$ PRF exudate $(0.1290 \pm 0.017 ; \mathrm{E})$ and $20 \%$ PRF exudate $(0.1280 \pm 0.002 ; \mathrm{F})$, Scale bar $=30 \mu \mathrm{m}$. 
Table 2. One way-ANOVA and LSD post-hoc statistical test for the effects of FBS, SFM and PRF different concentrations on hDPSCs osteodifferentiation

\begin{tabular}{ccc}
\hline $\begin{array}{c}\text { One way-ANOVA } \\
\text { (F ratio and } p \text { value })\end{array}$ & \multicolumn{2}{c}{ LSD post hoc test } \\
\hline One way-ANOVA & Concentration & (mean \pm SD) \\
\hline$\left(42.262,0.001^{*}\right)$ & $10 \%$ FBS & $0.1095^{\dagger} \pm 0.004$ \\
& SFM & $0.1273^{\dagger} \pm 0.006$ \\
& $1 \%$ PRF & $0.1913^{\dagger} \pm 0.006$ \\
& $5 \%$ PRF & $0.1273^{\dagger} \pm 0.006$ \\
& $10 \%$ PRF & $0.1290^{\dagger} \pm 0.017$ \\
& $20 \%$ PRF & $0.1280^{\dagger} \pm 0.002$ \\
& Total & $0.1354^{\dagger} \pm 0.027$ \\
\hline
\end{tabular}

LSD: least significant difference, ANOVA: analyses of variance, FBS: fetal bovine serum, SFM: serum free medium, PRF: platelet rich fibrin.

$\mathrm{p}<0.05$.

*One way-ANOVA.

${ }^{\dagger}$ Significant increase compared to $10 \%$ FBS.

were $0.1273 \pm 0.006, \quad 0.1273 \pm 0.006, \quad 0.1290 \pm 0.017$ and $0.1280 \pm 0.002$, respectively (Table 2, Fig. 5). There were significant differences between 10\% FBS \& SFM, 10\% FBS \& 1\% PRF, $10 \%$ FBS \& $5 \%$ PRF, $10 \%$ FBS \& 10\% PRF, 10\% FBS \& 20\% PRF, SFM \& 1\% PRF, $1 \%$ PRF \& $5 \%$ PRF, $1 \%$ PRF \& $10 \%$ PRF, $1 \%$ PRF \& 20\% PRF (Table 2, Fig. 5).

\section{Discussion}

Despite the eagerness around the clinical application of DPSCs, there are still certain challenges that have to be under control before regenerative approaches can be used as a routine therapy. One of the major concerns is to control the behavior of these cells in-vitro. It is well known that FBS is a universal growth supplement of cell and tissue culture media but serious ethical concerns were raised with regard to the welfare of the donor fetuses and besides FBS may contain adverse factors, like endotoxin, mycoplasma, viral contaminants or prion proteins. Therefore, the present study aimed to investigate an alternative to FBS to promote proliferation and osteodifferentiation of hDPSCs in-vitro.

From the methodological view point and in the present study, hPRF exudate was prepared by direct, easy, cheap and fast method through collecting the blood samples quickly and without exposure to air avoiding blood coagulation before centrifugation. All collected exudate was stored in $-20^{\circ} \mathrm{C}$ immediately to avoid denaturation of its proteins. Contrary, hPRF exudate was prepared in a pre-

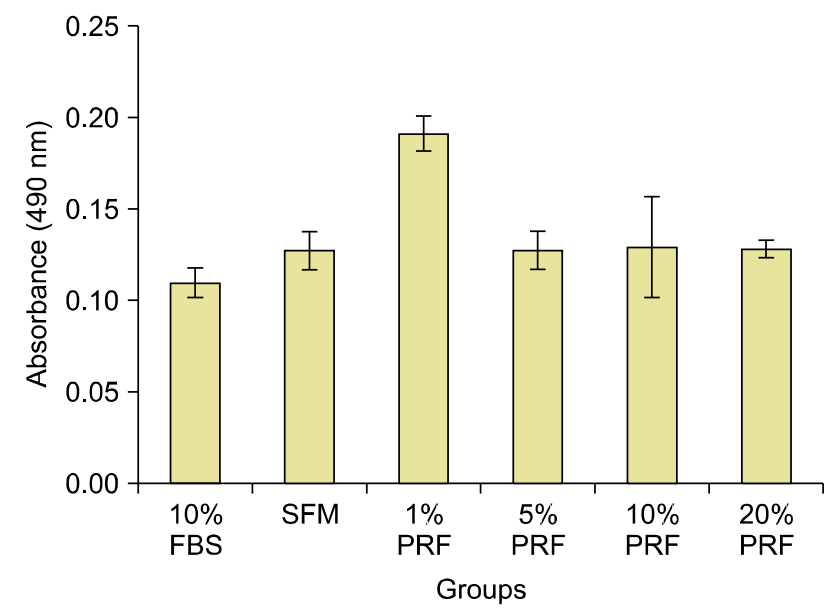

Fig. 5. Bar chart for the quantification of calcium mineral deposits of hDPSCs via dissolving the dye and subsequent absorption measurement at $405 \mathrm{~nm}$, measuring the efficiency of FBS, SFM and the PRF different concentrations for mineralized nodule formation, data are the mean $\pm S D$.

vious study by indirect method through adding $5 \mathrm{ml}$ of alpha modified Eagle medium ( $\alpha$-MEM) to PRF and they were incubated at $37^{\circ} \mathrm{C}$ and $5 \% \mathrm{CO}_{2}$. All collected exudate was stored at $-80^{\circ} \mathrm{C}$ before use. The $\alpha$-MEM enriched with exudate is considered as the $100 \%$ exudate (13).

Furthermore, in the previous studies $(15,16)$, the outer surfaces of the extracted teeth were cleaned using sterile instruments and brought in $\alpha$ MEM supplemented with $300 \mathrm{IU} / \mathrm{mL}$ penicillin, $300 \mu \mathrm{g} / \mathrm{mL}$ streptomycin and 0,75 $\mu \mathrm{g} / \mathrm{mL}$ amphotericin B. Meanwhile, in our study the extracted teeth were irrigated with normal saline to remove blood from its external surfaces. In addition, irrigation with $70 \%$ ethyl chloride was carried out providing some sort of protection against microbial infection and this step was followed by irrigation with PBS to remove any remnants of ethyl chloride which might affect pulp vitality. The extracted teeth were brought to the laboratory in commercial pasteurized whole milk. The commercial pasteurized whole milk is considered by the International Association of Dental Traumatology and the American Academy of Pediatric Dentistry as the best interim transporting medium for teeth. It is isotonic liquid with a physiologically compatible $\mathrm{pH}$ and osmolality (17).

To the best of our knowledge, this is the first study used the Hand Handle Held Pulp Isolator device for pulp tissue harvesting. The idea of using that device was for achieving tooth splitting without heat generation that might affect pulp vitality and liability for microbial infection. Furthermore, the DPSCs were isolated by the outgrowth expansion technique. Each pulp was cut into 10 fragments 
horizontally by 2 scalpels in cross manner to minimize tension and tearing of the pulp tissue. This was done in consistent with the method described by Batouli et al. (18). This was simple, easy, low cost and fast method. In the previous studies $(19,20)$, the enzymatic digestion method was the most commonly used procedure for DPSCs isolation. However it is expensive, time consuming and allows different cell types to develop. Nakashima (19) reported three different morphologies of DPSCs while Huang et al. (20) showed compact and loose colony types after enzymatic digestion.

Regarding the culture media, the DMEM-F12 was used in the present study as it is an extremely rich and complex medium that supports growth of wide range of cell types in both serum and serum-free formulation (18). Contrary, the nutritional media used in previous studies was $\alpha$-MEM $(21,22)$. This type of media should be supplemented with serum to be suitable for a wide range of mammalian cells. DMEM-F12 has twice the concentration of amino acids and four times the amount of vitamins compared to $\alpha$-MEM.

In this study the cells proliferation rate was measured by MTS assay. MTT protocol includes a liquid handling step to solubilize formazan precipitates during the assay, thus making the protocols less convenient $(23,24)$. The results of this study showed that proliferation rate was superior using $10 \%$ PRF exudate at the $1^{\text {st }}$ day, compared with $10 \%$ FBS. This proliferative capacity was inhibited at the $3^{\text {rd }}$ day but still more higher compared to the other concentrations. Therefore using $10 \% \mathrm{hPRF}$ exudate is preferable and recommended than $10 \%$ FBS, especially in clinical trials for regenerative therapy. In the previous studies, the optimum concentration of PRP varied from $50 \%$ to $10 \%(25,26)$ to less than $1 \%(27)$. Soffer et al. (27) considered $0.5 \sim 1 \% \mathrm{PRP}$ as the optimum concentration for cellular proliferation and mineralization rates. However, Ferreira et al. (25) found that 50\% PRP was the optimum concentration for osteoblast proliferation. On the other hand, 10\% PRP was sufficient to induce a marked cell proliferation of MSC, derived from adipose tissue (28). In addition, 5\% PL considered as the optimum concentration for MSC and DPSCs proliferation and osteogenesis (29).

Considering the osteogenic capability, 1\% PRF exudate induced the osteogenic differentiation of DPSCs more than the other concentrations, at the $7^{\text {th }}$ days. Therefore using this concentration is recommended especially in bone wound healing and tissue engineering. The previous studies showed that the optimum concentration for the formation of calcium deposits was 2\% PRP for DPSCs and human periodontal ligament stem cells, while $1 \%$
PRP resulted in the highest calcium deposits in human exfoliated deciduous teeth (30). Contrary, Karbanová et al. (31) concluded that certain environmental cues like TGF-beta3 and BMP-2 can enhance differentiation process of DPSCs into osteogenic lineage, which suggest their possible utilization in tissue engineering. In addition, Mori et al. (32) indicate that DPSCs show a correct osteoblastic phenotype and during the osteoblastic differentiation process, IGFBP-5, JunB, and NURR1 gene expression is significantly increased.

\section{Conclusion}

On the base of our study results; 10\% PRF exudate was the optimum concentration for hDPSCs proliferation, while $1 \%$ PRF exudate was the optimum concentration for osteodifferentiation of DPSCs and mineralized nodules formation.

\section{Potential conflict of interest}

All authors deny any conflict of interest.

\section{References}

1. Trubiani O, Diomede F. Xeno-free culture of human periodontal ligament stem cells. Methods Mol Biol 2015; 1283:87-92

2. Crespo-Diaz R, Behfar A, Butler GW, Padley DJ, Sarr MG, Bartunek J, Dietz AB, Terzic A. Platelet lysate consisting of a natural repair proteome supports human mesenchymal stem cell proliferation and chromosomal stability. Cell Transplant 2011;20:797-811

3. Tekkatte C, Gunasingh GP, Cherian KM, Sankaranarayanan K. "Humanized" stem cell culture techniques: the animal serum controversy. Stem Cells Int 2011 doi:10.4061/2011/ 504723

4. Lindroos B, Boucher S, Chase L, Kuokkanen H, Huhtala $H$, Haataja R, Vemuri $M$, Suuronen $R$, Miettinen S. Serum-free, xeno-free culture media maintain the proliferation rate and multipotentiality of adipose stem cells in vitro. Cytotherapy 2009;11:958-972

5. Wu RX, Yu Y, Yin Y, Zhang XY, Gao LN, Chen FM. Platelet lysate supports the in vitro expansion of human periodontal ligament stem cells for cytotherapeutic use. J Tissue Eng Regen Med 2016 doi:10.1002/term.2124

6. Kocaoemer A, Kern S, Klüter H, Bieback K. Human AB serum and thrombin-activated platelet-rich plasma are suitable alternatives to fetal calf serum for the expansion of mesenchymal stem cells from adipose tissue. Stem Cells 2007;25:1270-1278

7. Hemeda H, Giebel B, Wagner W. Evaluation of human platelet lysate versus fetal bovine serum for culture of mesenchymal stromal cells. Cytotherapy 2014;16:170-180

8. Suri K, Gong HK, Yuan C, Kaufman SC. Human platelet 
lysate as a replacement for fetal bovine serum in limbal stem cell therapy. Curr Eye Res 2016;41:1266-1273

9. do Amaral RJ, Matsiko A, Tomazette MR, Rocha WK, Cordeiro-Spinetti E, Levingstone TJ, Farina M, O'Brien FJ, El-Cheikh MC, Balduino A. Platelet-rich plasma releasate differently stimulates cellular commitment toward the chondrogenic lineage according to concentration. J Tissue Eng 2015;6:2041731415594127

10. Chou ML, Burnouf T, Wang TJ. Ex vivo expansion of bovine corneal endothelial cells in xeno-free medium supplemented with platelet releasate. PLoS One 2014;9:e99145

11. Wasterlain AS, Braun HJ, Harris AH, Kim HJ, Dragoo JL. The systemic effects of platelet-rich plasma injection. Am J Sports Med 2013;41:186-193

12. Kobayashi M, Kawase T, Okuda K, Wolff LF, Yoshie H. In vitro immunological and biological evaluations of the angiogenic potential of platelet-rich fibrin preparations: a standardized comparison with PRP preparations. Int J Implant Dent 2015;1:31

13. He L, Lin Y, Hu X, Zhang Y, Wu H. A comparative study of platelet-rich fibrin (PRF) and platelet-rich plasma (PRP) on the effect of proliferation and differentiation of rat osteoblasts in vitro. Oral Surg Oral Med Oral Pathol Oral Radiol Endod 2009;108:707-713

14. Lin CS, Xin ZC, Dai J, Lue TF. Commonly used mesenchymal stem cell markers and tracking labels: Limitations and challenges. Histol Histopathol 2013;28:1109-1116

15. Gregory CA, Gunn WG, Peister A, Prockop DJ. An Alizarin red-based assay of mineralization by adherent cells in culture: comparison with cetylpyridinium chloride extraction. Anal Biochem 2004;329:77-84

16. Dissanayaka WL, Zhu X, Zhang C, Jin L. Characterization of dental pulp stem cells isolated from canine premolars. J Endod 2011;37:1074-1080

17. Berridge MV, Herst PM, Tan AS. Tetrazolium dyes as tools in cell biology: new insights into their cellular reduction. Biotechnol Annu Rev 2005;11:127-152

18. Batouli S, Miura M, Brahim J, Tsutsui TW, Fisher LW, Gronthos S, Robey PG, Shi S. Comparison of stem-cellmediated osteogenesis and dentinogenesis. J Dent Res 2003; 82:976-981

19. Nakashima M. Establishment of primary cultures of pulp cells from bovine permanent incisors. Arch Oral Biol 1991;36:655-663

20. Huang XF, Yuan SJ, Yang C. Effects of total flavonoids from Drynaria fortunei on the proliferation and osteogenic differentiation of rat dental pulp stem cells. Mol Med Rep 2012;6:547-552

21. Gronthos S, Mankani M, Brahim J, Robey PG, Shi S.
Postnatal human dental pulp stem cells (DPSCs) in vitro and in vivo. Proc Natl Acad Sci U S A 2000;97:13625-13630

22. Abuarqoub D, Awidi A, Abuharfeil N. Comparison of osteo/odontogenic differentiation of human adult dental pulp stem cells and stem cells from apical papilla in the presence of platelet lysate. Arch Oral Biol 2015;60:1545-1553

23. Scudiero DA, Shoemaker RH, Paull KD, Monks A, Tierney S, Nofziger TH, Currens MJ, Seniff D, Boyd MR. Evaluation of a soluble tetrazolium/formazan assay for cell growth and drug sensitivity in culture using human and other tumor cell lines. Cancer Res 1988;48:4827-4833

24. Tada H, Shiho O, Kuroshima K, Koyama M, Tsukamoto K. An improved colorimetric assay for interleukin 2. J Immunol Methods 1986;93:157-165

25. Ferreira CF, Carriel Gomes MC, Filho JS, Granjeiro JM, Oliveira Simões CM, Magini Rde S. Platelet-rich plasma influence on human osteoblasts growth. Clin Oral Implants Res 2005;16:456-460

26. Lucarelli E, Beccheroni A, Donati D, Sangiorgi L, Cenacchi A, Del Vento AM, Meotti C, Bertoja AZ, Giardino R, Fornasari PM, Mercuri M, Picci P. Platelet-derived growth factors enhance proliferation of human stromal stem cells. Biomaterials 2003;24:3095-3100

27. Soffer E, Ouhayoun JP, Anagnostou F. Fibrin sealants and platelet preparations in bone and periodontal healing. Oral Surg Oral Med Oral Pathol Oral Radiol Endod 2003;95: 521-528

28. Castegnaro S, Chieregato K, Maddalena M, Albiero E, Visco C, Madeo D, Pegoraro M, Rodeghiero F. Effect of platelet lysate on the functional and molecular characteristics of mesenchymal stem cells isolated from adipose tissue. Curr Stem Cell Res Ther 2011;6:105-114

29. Govindasamy V, Ronald VS, Abdullah AN, Ganesan Nathan KR, Aziz ZA, Abdullah M, Zain RB, Kasim NH, Musa S, Bhonde RR. Human platelet lysate permits scale-up of dental pulp stromal cells for clinical applications. Cytotherapy 2011;13:1221-1233

30. Chevallier N, Anagnostou F, Zilber S, Bodivit G, Maurin S, Barrault A, Bierling P, Hernigou P, Layrolle P, Rouard H. Osteoblastic differentiation of human mesenchymal stem cells with platelet lysate. Biomaterials 2010;31:270-278

31. Karbanová J, Soukup T, Suchánek J, Mokrý J. Osteogenic differentiation of human dental pulp-derived stem cells under various ex-vivo culture conditions. Acta Medica (Hradec Kralove) 2010;53:79-84

32. Mori G, Brunetti G, Oranger A, Carbone C, Ballini A, Lo Muzio L, Colucci S, Mori C, Grassi FR, Grano M. Dental pulp stem cells: osteogenic differentiation and gene expression. Ann N Y Acad Sci 2011;1237:47-52 